\title{
Dyeing of cotton with natural dyes from Bluebell vine, Globe amaranth, Marigold and Shoe flower
}

\author{
S.Sreeranjini $^{1 *}$, P S Akshaya Pradeep ${ }^{2}$ \\ ${ }^{1}$ Department of Post-Graduate Studies and Research in Botany, Sanatana Dharma College, Alappuzha, India \\ ${ }^{2}$ Department of Post-Graduate Studies and Research in Botany, Sanatana Dharma College, Alappuzha, India \\ *Corresponding author e mail:sreeranjinis80@gmail.com
}

Available online at: www.isroset.org

Received: 19/Mar/2019, Accepted: 13/Apr/ 2019, Online: 31/Apr/2019

\begin{abstract}
Natural dyes are known for their use in coloring of food substrate, leather as well as natural fibers like wool, silk and cotton as major areas of application since pre-historic times. In the present study, dyeing pigments were extracted from the flowers of blue bell vine, globe amaranth, marigold and shoe flower and application on cotton fabrics were analyzed. Two mordants ferrous sulphate and copper sulphate were used. The result revealed that different shades were obtained from the dyes when subjected to mordant treatments. Dyes obtained from these flowers can be utilized for various industries such as textile, cosmetics, leather, food and pharmaceuticals.
\end{abstract}

Keywords-Natural dyes, Flower dyes, Mordants, Cotton.

\section{INTRODUCTION}

India harbors a wealth of useful germplasm resources and there is no doubt that the plant kingdom is a treasure-house of diverse natural products .One such product from nature is the dye [1]. For thousands of years, and about a century ago, the color of fabrics came chiefly from the crude juices of plants. The use of the indigo plant for dyeing fabrics blue dates beyond 3000 B.C [2]. Almost all the synthetic colorants being synthesized from petrochemical sources through hazardous chemical processes posses threat towards its eco-friendliness [3]. Hence, worldwide, growing consciousness about organic value of eco-friendly products has generated renewed interest of consumers towards use of textiles (preferably natural product) dyed with eco-friendly natural dyes. Natural dyes are extracted from the roots, stems, leaves, flowers, fruits of various plants, dried bodies of certain insects and minerals [4]. Many of these natural dyes are reported to have antimicrobial activities [5].

Some of the well-known ancient dyes include madder, a red dye made from the roots of the Rubia tinctorum L., blue indigo from the leaves of Indigofera tinctoria L., and from turmeric (Curcuma longa L.) [6]. Flowers are an important source of natural dyes [7]. Saffron has been widely used as fabric dye and as food colorant. Saffron comes from the stigmas of Crocus sativus. This stigmas produce yellow pigment which is a rich source of vitamin riboflavin [8]. The present study aimed to extract dyes from the flowers of
Bluebell wine, Globe amaranth, Marigold, Shoe flower and its application in cotton fabrics.

\section{MATERIALS AND METHODS}

\subsection{Source of natural dyes}

The flowers of four different plants were collected from near by areas of Sanatana Dharma College campus. The natural dye source were represented in Table 1 . The dyeing of the cotton fabric was done in four different stages, extraction of colorant, scouring of cotton, mordanting and dyeing [9].

Table 1. Details of natural dye source

\begin{tabular}{|c|c|c|c|}
\hline Scientific Name & Common name & Plant Part & Colour \\
\hline Clitoria ternatea L. & Blue bell vine & Flower & Blue \\
\hline Gomphrena globosa L. & Globe amaranth & Flower & Purple \\
\hline Tagetes erecta L. & Marigold & Flower & Orange \\
\hline Hibiscus rosa-sinensis L. & Shoeflower & Flower & Red \\
\hline
\end{tabular}

\subsection{Extraction and dyeing}

The samples were cleaned using distilled water. $50 \mathrm{~g}$ of fresh flowers were boiled in $500 \mathrm{ml}$ distilled for 2 hours in a hot water bath. After 2 hours, the extracted color was double filtered. For scouring cotton fabrics were washed in a solution containing $0.5 \mathrm{~g} / \mathrm{L}$ sodium carbonate and $2 \mathrm{~g} / \mathrm{L}$ non ionic detergent solution at $50^{\circ} \mathrm{C}$ for 25 minutes. The scoured material was thoroughly washed with tap water and dried at 
room temperature. The scoured material was soaked in distilled water for 30 minutes prior for mordanting

Ferrous sulphate and Copper sulphate were the two mordants analysed in the present study. $16 \mathrm{~g}$ mordant was dissolved in $200 \mathrm{ml}$ distilled water to make the solution. The cotton fabrics were treated with the mordant solution at $80^{\circ}$ $\mathrm{C}$ for a period of half an hour and were left in that state for another half an hour. The mordanted material was then rinsed with water thoroughly squeezed and dried The dried cotton fabrics was dyed with colorant directly and gently boiled for 45 minutes by maintaining the temperature at $75^{\circ}$ C. The samples were kept overnight along with the boiled flower extract and next day it was air dried. The absorption spectra of the dyed fabrics were measured using a UV-VIS spectrophotometer (Shimadzu 2400).

\section{RESULT AND DISCUSSION}

Deep blue color pigment was obtained from bluebell vine (Fig 1 a). Purple color from globe amaranth and orange yellowish color from marigold(Fig 1 b,c). Reddish brown colored pigment were obtained from shoe flower (Fig $1 \mathrm{~d}$ ). Two mordants showed different color in cotton fabrics when treated with blue dye from blue bell vine. Copper sulphate mordant treated fabric showed light blue color and ferrous sulphate mordant treated fabric resulted in pale blue coloration (Fig 2.a,b.). Mordants used in the present study were not found to be effective in purple colored dye from globe amaranth. Copper sulphate mordant treated fabric showed light yellow colour and ferrous sulphate mordant treated fabric resulted in Peach coloration (Fig 2.c,d).

Orange yellowish colored dye extracted from marigold showed dark yellow color in copper sulphate mordant treated fabric and ferrous sulphate mordant treated fabric resulted in a brownish shade with uniform spreading (Fig 3.a,b). ). Even though reddish brown colored dye was extracted from shoe flowers the mordant treated fabric resulted in new color with the red dye. Copper sulphate mordant treated fabric showed grey color while ferrous sulphate mordant treated fabric resulted in a blue shade with uniform spreading (Fig 3.c,d). Dyeing textile using natural dyes was found to yield poor color, have inadequate fastness properties. To overcome such hassle mordants are used. Mordanting must be capable of combining chemicals with the coloring matter (the dye) being applied, while a few plant dyes may be used directly. The majority require a mordant for permanent color [10]. FesO4 and $\mathrm{CuSO} 4$ used as mordants in the present study imparted different colours to the fabrics with natural dyes. Mordants can create extensive variation in colors by their type and concentration [11]. Ferrous sulphate and Copper sulphate have the ability of forming co-ordination complexes. Functional groups such as amino and carboxylic acid on the fiber can occupy the unoccupied sites on interaction with the fiber. Thus, a ternary complex is formed by the metal salt on which one site is with the fiber and the other site is with the dye. Metal ions of mordants act as electron acceptors for electron donors to form co-ordination bonds with the dye molecule, making them insoluble in water [12]. Common mordants used are alum, chrome, stannous chloride, copper sulphate, ferrous sulphate etc [13]. Combination of mordants can successfully used for dyeing of cotton to obtain a wide range of soft and light colours [14].The absorption spectra of the dyed fabrics were measured using a UV-VIS spectrophotometer. The absorbtion was noticed in a wavelength range between 300 to $600 \mathrm{~nm}$. Maximum absorbtion was noticed in marigold, shoeflower and bluebellvine (Fig 4).

\section{CONCLUSION}

The present investigation aimed to analyze the effectiveness of natural dyes extracted from the flowers of four plants on cotton fabrics. Among the four members analyzed it was noticed that these flower dyes are imparting different color shades on cotton fabrics. So these natural dyes can be replaced for synthetic dyes since they don't have side effects.

\section{Acknowledgement}

The authors are thankful to Dr. V S Harikumar, Head, Department of Post Graduate studies and research in Botany, Sanatana Dharma College, Alappuzha for the facilities provided.

\section{REFERENCES}

[1]. R. Siva, "Status of natural dyes and dye yielding plants in India", Current Science, Vol. 92, Issue.7, pp.916-925, 2007.

[2]. P.Kaufman, L. Cseke, A. Kirakosyan, S. Warber, J. Duke, H. Brielmann, Natural Products from Plants, 2nd ed. CRC Press/Taylor and Francis Group, pp-616, 2006.

[3]. A.K. Samanta , Agarwal , Application of natural dye on textile", Indian Journal of Fiber and Textile Research, Vol. 34, Issue. 4, pp.384-399, 2009.

[4]. S.P. Vankar, "Chemistry of natural dyes", Resonance, Vol. 5, Issue. 10, pp.73-80, 2000.

[5]. R. Singh, A. Jain, S. Panwan, D. Gupta, S.K. Khare, "Antimicrobial activity of natural dyes", Dyes and pigments, Vol.66, Issue.2, pp 99-102, 2005.

[6]. K.V. Krishnamurthy, R. Siva, T.Senthil Kumar, "Natural dyeyielding plants of Shervaroy Hills of Eastern Ghats". Proceedings of National Seminar on the conservation of Eastern Ghats, Environment Protection, Training and Research Institute, Hyderabad 151-153,2002.

[7]. R. Singh, S. SrivastavA, “ Exploration of flower based natural dyes-A review", Research Journal of Recent Sciences Vol.4, pp68, 2015.

[8]. A.S.M. Raja, P.K. Pareek, D.B. Shakyawar, S.A. Wani S, A.H. Sofi, " Extraction of natural dye from saffron flower waste and its application in pashmina fabric", Advances in applied science Research, Vol.3, Issue.1, pp56-161, 2012.

[9]. D. Baishya , J. Talukdar , S. Sandhya , "Cotton dying with natural dye extracted from flower of Bottlebrush (Callistemon 
citrinus)", Universal Journal of Environmental Research and Technology, Vol. 2, Issue.5, pp 377-382, 2012.

[10]. T. Sahoo, G. Bhattacharya, S.K. Dash, "Effectiveness of Different Mordants and Concentrations on the Dyeing Properties of Jackfruit (Atrocarpus heterophyllus) Bark on Silk", International Journal of Agriculture, Environment and Biotechnology Vol.10, Issue.55, pp65-573, 2017.

[11]. M. Kumaresan, P.N. Palanisamy, P.E. Kumar, " Application of ecofriendly natural dye on silk using combination of mordants", International Journal of Chemistry Research., Vol.2, Issue.1, pp11-14, 2011.
[12]. R. Mongkholrattanasit, J. Krystufek, J. Wiener, M.Vikova, “ Dyeing, Fastness and UV Protection Properties of Silk And Wool Fabrics Dyed with Eucalyptus Leaf Extract by the Exhaustion Process", Fibers and Textiles, Vol.19, Issue. 3, pp94-99, 2011.

[13]. S.S. Kulkarni, U.M. Bodake, G.R. Pathade, "Extraction of Natural Dye from Chili(Capsicum Annum) for Textile Coloration" Universal Journal of Environmental Research and Technology, Vol.1, Issue.1, pp58-63,2011.

[14]. M. Kumaresan, P.N. Palanisamy, P.E. Kumar, "Application of Eco-friendly Natural Dye Obtained from Corida sebestena on Cotton using Combination of Mordants", Journal of Natural Product and Plant Resources, Vol.2, Issue.1, pp 32- 38, 2012.
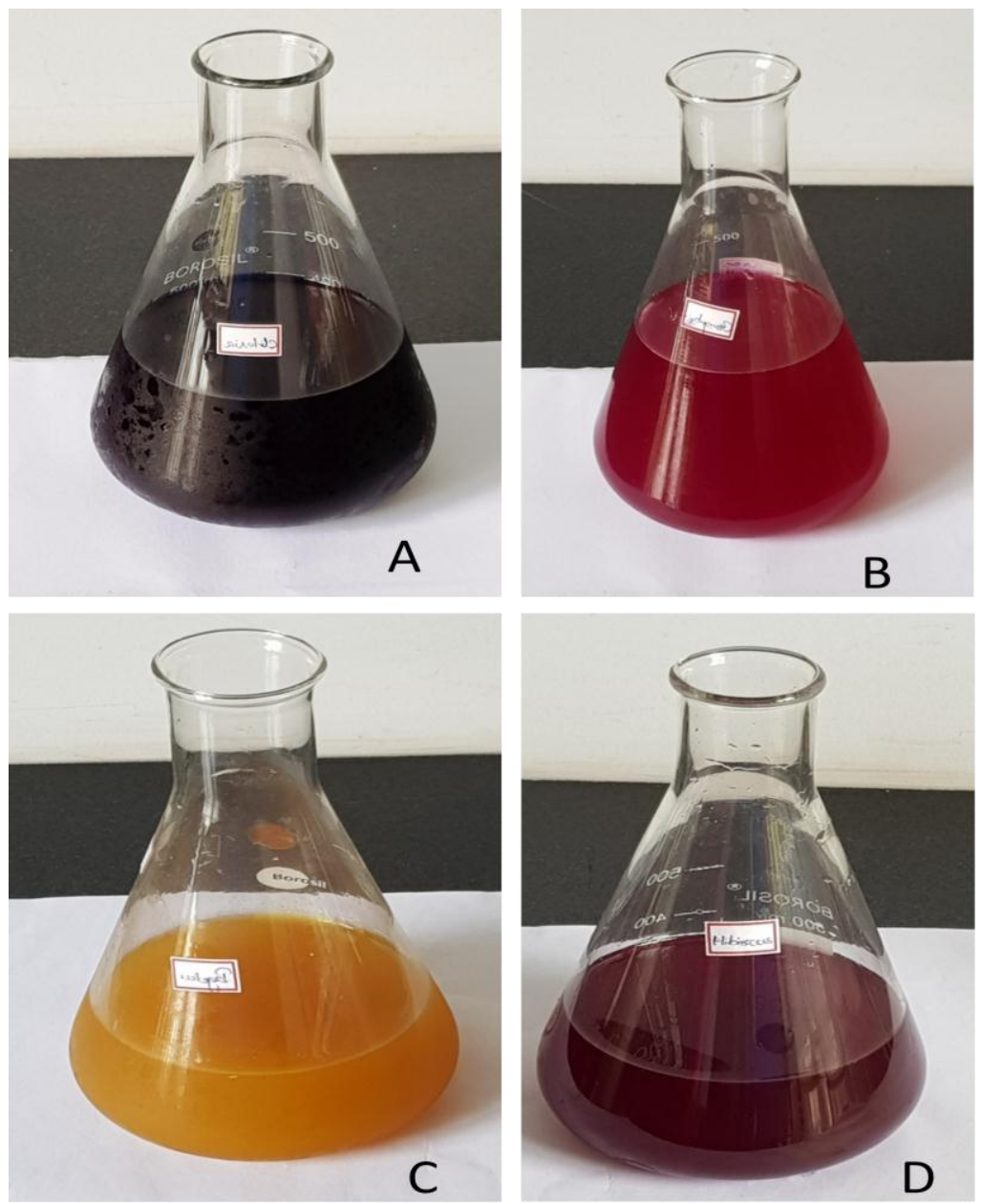

Figure 1. Dye extracted from A.Blue bell vine B. Globe amaranth C. Marigold D. Shoe flower 

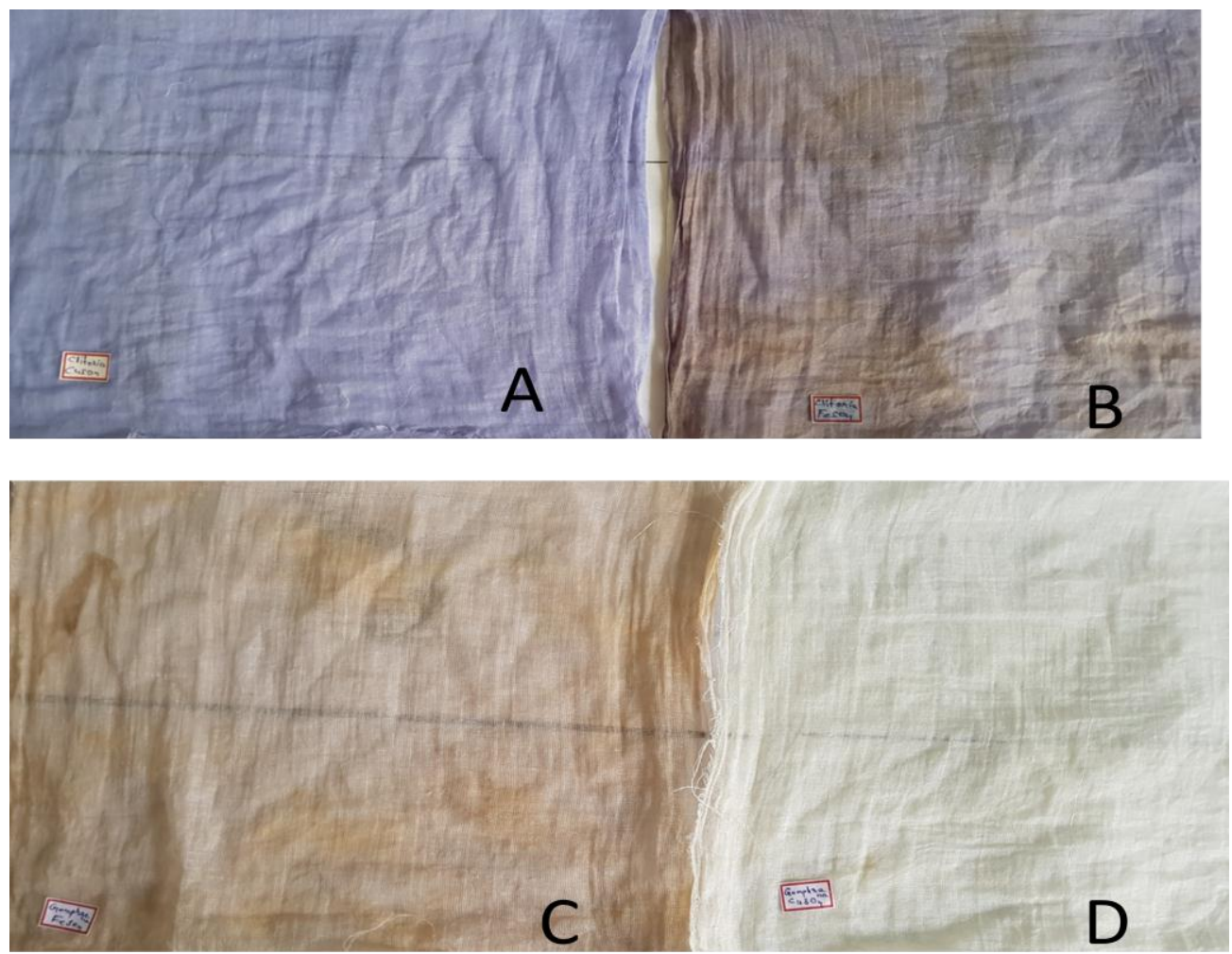

Figure 2. Cotton fabric dyed with blue bell vine (a,b) Globe amaranth (c,d).
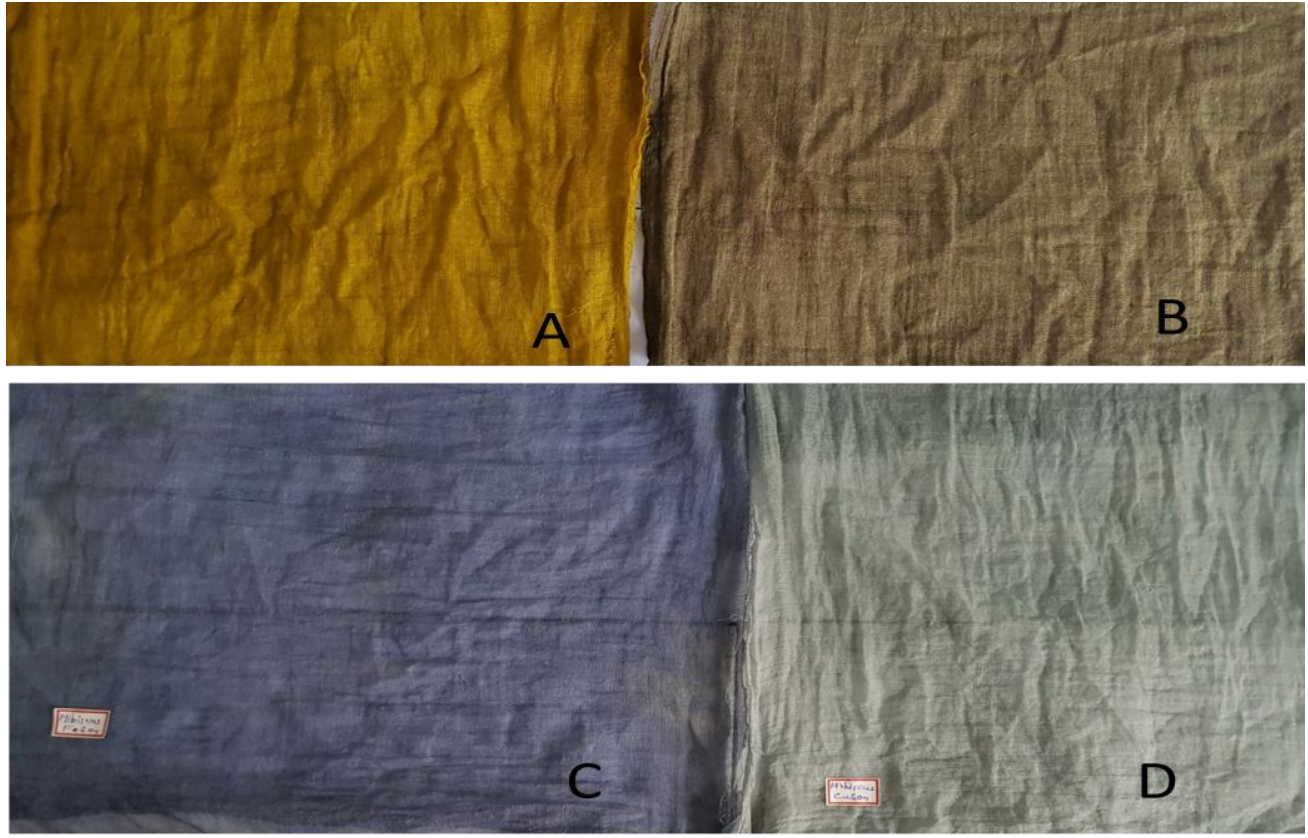

Figure 3. Cotton fabric dyed with Marigold (a,b) Shoe flower (c,d). 

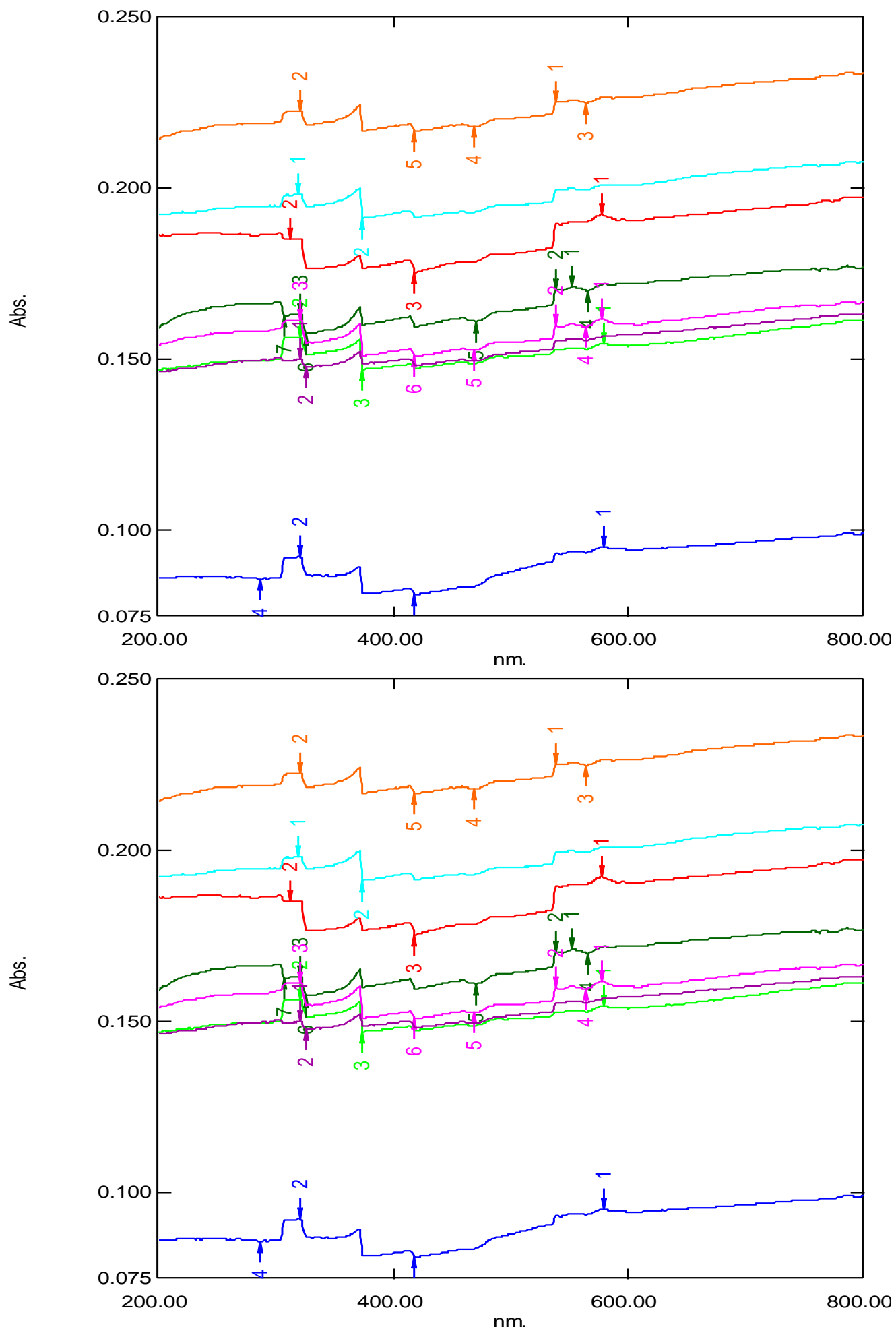


\begin{tabular}{|c|c|c|c|}
\hline Name & Mordant & Wav elength & Absorbtion \\
\hline \multirow[t]{3}{*}{ Ctitoria ternatea } & \multirow[t]{2}{*}{$\mathrm{FesO} 4$} & 538 & 0.225 \\
\hline & & 320 & 0.223 \\
\hline & $\mathrm{CuSO} 4$ & 319 & 0.198 \\
\hline \multirow[t]{4}{*}{ Gomphrena globosa } & \multirow[t]{3}{*}{ FesO4 } & 552 & 0.171 \\
\hline & & 539 & 0.170 \\
\hline & & 320 & 0.163 \\
\hline & CuSO4 & 320 & 0.150 \\
\hline \multirow[t]{4}{*}{ Tagetes erecta } & \multirow[t]{2}{*}{$\mathrm{FesO} 4$} & 577 & 0.192 \\
\hline & & 313 & 0.185 \\
\hline & \multirow[t]{2}{*}{$\mathrm{CuSO} 4$} & 579 & 0.095 \\
\hline & & 320 & 0.092 \\
\hline \multirow{5}{*}{$\begin{array}{l}\text { Hibiscustosa- } \\
\text { sinensis }\end{array}$} & \multirow[t]{2}{*}{$\mathrm{FesO} 4$} & 579 & 0.155 \\
\hline & & 320 & 0.157 \\
\hline & \multirow[t]{3}{*}{$\mathrm{CuSO} 4$} & 578 & 0.162 \\
\hline & & 538 & 0.160 \\
\hline & & 320 & 0.168 \\
\hline
\end{tabular}

Figure 4.Absorbtion spectra of dyed fabrics

\section{Authors profile}

Dr. Sreeranjini S pursed Ph.D in Botany from Department of Botany, University of Kerala in 2014. She is currently working as Assistant Professor in Department of Post Graduate Studies and Research in Botany, Sanatana Dharma College, Alappuzha, Kerala since 2014. She has published 5 research papers in reputed international journals including Proceedings of the national Academy of Sciences India section Life Sciences, Springer and have more than ten presentations in national and International seminars. Her main area of research is plant tissue culture especially in dye yielding plants. She has 8 years of teaching experience and 9 years of research experience. 